\title{
Highly efficient production of an influenza H9N2 vaccine using MDCK suspension cells
}

\author{
Yixiao Wu ${ }^{1}$, Hanjing Jia ${ }^{1}$, Hanzhang Lai ${ }^{2,3}$, Xuping Liu ${ }^{1,4^{*}}$ and Wen-Song Tan ${ }^{1}$
}

\begin{abstract}
The use of H9N2 subtype avian influenza vaccines is an effective approach for the control of the virus spread among the poultry, and for the upgrading of vaccine manufacturing, cell culture-based production platform could overcome the limitations of conventional egg-based platform and alternate it. The development of serum-free suspension cell culture could allow even higher virus productivity, where a suspension cell line with good performance and proper culture strategies are required. In this work, an adherent Mardin-Darby canine kidney (MDCK) cell line was adapted to suspension growth to cell concentration up to $12 \times 10^{6} \mathrm{cell} / \mathrm{mL}$ in a serum-free medium in batch cultures. Subsequently, the H9N2 influenza virus propagation in this MDCK cell line was evaluated with the optimization of infection conditions in terms of $\mathrm{MOl}$ and cell concentration for infection. Furthermore, various feed strategies were tested in the infection phase for improved virus titer and a maximum hemagglutinin titer of $13 \log _{2}$ ( $\mathrm{HAU} / 50 \mu \mathrm{L}$ ) was obtained using the 1:2 medium dilution strategy. The evaluation of MDCK cell growth and H9N2 virus production in bioreactors with optimized operating conditions showed comparable cell performance and virus yield compared to shake flasks, with a high cell-specific virus yield above 13,000 virions/cell. With the purified H9N2 virus harvested from the bioreactors, the MDCK cell-derived vaccine was able to induce high titers of neutralizing antibodies in chickens. Overall, the results demonstrate the promising application of the highly efficient MDCK cell-based production platform for the avian influenza vaccine manufacturing.
\end{abstract}

Keywords: MDCK suspension cells, Cell adaptation, Influenza virus, Feed strategy, Cell culture-based vaccine manufacturing

\section{Introduction}

Avian influenza virus (AIV) can cause infections both in animals and humans. The H9N2 viruses have been isolated globally in the past few decades and are persistently circulating in several countries in Asia, the Middle East, and North Africa (Gu et al. 2017). This has resulted in severe economic burdens to the poultry industry by the decrease in egg production and the moderate-to-high mortality of poultry (Lamb and Takeda 2001; Lee and Song 2013; Pu et al. 2015). In addition, H9N2 viruses have revealed the potential to cause the pandemic due

\footnotetext{
*Correspondence: xupingliu@ecust.edu.cn

${ }^{1}$ State Key Laboratory of Bioreactor Engineering, East China University of Science and Technology, 130 Meilong Road, P. O. Box 309\#,

Shanghai 200237, China

Full list of author information is available at the end of the article
}

to the emerging reported cases of avian-to-human transmission of H9N2 viruses and detections of partial H9N2 virus-derived genomic segments in the emerging highly pathogenic human influenza viruses regarding H7N9, $\mathrm{H} 5 \mathrm{~N} 1, \mathrm{H} 10 \mathrm{~N} 8$, and H5N6 virus reassortants (Gu et al. 2017; Li et al. 2014; Pu et al. 2017; Sorrell et al. 2009). To face the threat posed by the emerging H9N2 viruses, vaccination is considered as an effective measurement to control the virus spread among the poultry and to limit the health risks to humans (Genzel and Reichl 2009; Park et al. 2011).

The conventional embryonated egg production platform has been intensively applied for the manufacturing of influenza vaccines for more than 70 years. Nevertheless, this platform is highly dependent on the supplies of eggs, which can be limited in the event of an influenza pandemic (Hegde 2015; Ulmer et al. 2006). Furthermore, 
the influenza virus produced in eggs acquired the antigenic alteration in glycosylated proteins due to the hostcell adaptation, resulting in the vaccines less protective against some influenza strains (Zost et al. 2017). Cell culture-based platform has been established as a viable alternative for the manufacturing of influenza vaccines, particularly advantageous in case of a pandemic, due to its flexibility, scalability, and lower potential constraints of egg shortages (Harding and Heaton 2018; Milian and Kamen 2015). Particularly, the lately developed disposable equipment enables the fast and handy manufacturing of influenza vaccines (Coronel et al. 2019). Various continuous cell lines have been characterized for the propagation of influenza viruses, such as human embryonic kidney 293 (HEK293), Vero, EB66, PBG.PK2.1, DuckCelt ${ }^{\circledR}-\mathrm{T} 17$, and MDCK cells, among which the MDCK cells are considered as one of the most suitable candidates due to its high susceptibility to influenza virus and superior productivity for the increased production capacity (Brown and Mehtali 2010; Genzel et al. 2010; Granicher et al. 2019; Huang et al. 2015; Le Ru et al. 2010; Pau et al. 2001; Petiot et al. 2018). By using the MDCK cells, influenza vaccines, such as Flumist ${ }^{\circledR}$ (MedImmune), Flucelvax ${ }^{\circledR} /$ Optaflu $^{\circledR}$ (Seqirus/Novartis), and SKYCellflu ${ }^{\circledR}$ (SK chemicals), have been developed and certified (Genzel and Reichl 2009; Sun et al. 2011).

In past years, massive progress has been reported with the propagation of influenza virus using adherent MDCK cells (Bock et al. 2009; Genzel et al. 2006; Hu et al. 2008; Hussain et al. 2010). Nevertheless, the use of serum for cell growth leads to the increased complexity of culture process and batch-to-batch variations. In addition, desired high cell density cultivation is limited by the surface area of the microcarrier beads. The cell line and medium development can lead to MDCK suspension culture in serum-free or chemically defined medium, which enables the large-scale manufacturing of influenza vaccines due to the easy operation and the stable process control (Chu et al. 2009; Lohr et al. 2010). Particularly, the cell adaptation to suspension culture in a well-designed serum-free medium is required to reduce the risks of undesirable cell line properties regarding inadequate cell growth performance and low virus productivity. With the suspension cell line, for the process design and optimization to produce influenza vaccines, various process strategies need to be selected to maximize the cell concentration and virus titer as well as to avoid the socalled "cell density effect," which leads to the reduction of cell-specific virus yield (CSVY) (Maranga et al. 2003). Therefore, a combination of a suitable MDCK cell line and optimal process strategies is of a great importance for the efficient virus production in large-scale manufacturing. However, the growth performance of MDCK suspension cells regarding the aggregates, low cell growth rate, and low cell concentration have been reported (Chu et al. 2009; Huang et al. 2011; Li et al. 2018; Lohr et al. 2010). In addition, with low CSVYs, these MDCK suspension cells were not able to reach high virus titers. Furthermore, for avian influenza vaccines so far no study focuses on the systematical development of a simple and efficient suspension cell culture-based process from cell line generation to the immunogenicity evaluation of new vaccines.

In this work, we demonstrate the development of a highly efficient process for the production of an avian H9N2 vaccine using MDCK suspension cells. The adaptation of an adherent MDCK cell line to suspension growth in a serum-free medium was performed to allow the growth to high cell concentration at high cell growth rate. Furthermore, influenza virus productions with the adapted suspension cells were evaluated by implementing various feed strategies in the infection phase with the aim of increased virus yield. Additionally, the scale-up in bioreactors was compared to the cultivation in the shake flasks in terms of cell growth and virus production as well as the immunogenicity of the vaccine produced in bioreactors was evaluated. Overall, we demonstrate a highly potential production platform for the fast large-scale manufacturing of avian influenza vaccines.

\section{Materials and methods}

\section{Cell line and cell culture}

The adherent MDCK cell line (NBL-2) (ATCC, Virginia, USA; No. CCL-34) used in this work was cultivated in Dulbecco's modified Eagle's medium (DMEM; Thermo Fisher Scientific, Waltham, USA) supplemented with $10 \%(\mathrm{v} / \mathrm{v})$ of fetal bovine serum (FBS; Biosun, Shanghai, China) in static $\mathrm{T}$ flasks (TPP, Trasadingen, Switzerland) at $37{ }^{\circ} \mathrm{C}$ and $5 \% \mathrm{CO}_{2}$ atmosphere. After the adaptation to suspension growth, the MDCK cells were cultivated in an in-house serum-free medium, here referred as Xeno-SFM, in polycarbonate Erlenmeyer shake flasks (Corning ${ }^{\circledR}$, Corning, USA) at $37^{\circ} \mathrm{C}$ and $5 \% \mathrm{CO}_{2}$ atmosphere with a shaking frequency of $130 \mathrm{rpm}$. For the growth evaluation of suspension cells in shake flasks, cells were inoculated with a cell concentration of $1 \times 10^{6}$ cells $/ \mathrm{mL}$. For the process optimization in shake flasks, the cells were seeded and grown to $6 \times 10^{6}$ or $10 \times 10^{6}$ cells $/ \mathrm{mL}$ for infection. For the batch cultivation in the bioreactor, MDCK cells were cultivated in a $3 \mathrm{~L}$ bioreactor (ez-Control, Applikon, Delft, the Netherlands) with a working volume (wv) of $1 \mathrm{~L}$. Approximately $170 \mathrm{~mL}$ of the preculture was used to inoculate the bioreactor with a seed density of $1.0 \times 10^{6}$ cells $/ \mathrm{mL}$. The cells were grown for $72 \mathrm{~h}$ before infection. The $\mathrm{pH}$ was controlled at 7.00 by the addition of $1 \mathrm{M} \mathrm{NaOH}$ and $\mathrm{CO}_{2}$ flow through the 
sparger. The dissolved oxygen (DO) was set to $40 \%$ by the headspace aeration with a constant flow of air and a ring sparger with the air $-\mathrm{O}_{2}$ mixture in the culture. In addition, the temperature was controlled at $37{ }^{\circ} \mathrm{C}$ and agitation was set at $150 \mathrm{rpm}$ over the whole cultivation.

Cell concentration, viability, and diameter were measured by a cell counter (Countstar, Shanghai, China) based on the trypan blue staining method (Gao et al. 2016). 20 $\mu \mathrm{L}$ of fully adapted cell culture was applied to the microscope slide and the cell morphology was viewed by an ELIPSE microscope (NIKON, Tokyo, Japan) Extracellular metabolites regarding glutamine, glucose, lactate, and ammonium were measured by an automatic Bioprofile 400 analyzer (Nova Biomedical, Waltham, USA) (Lohr et al. 2009).

\section{Cell adaptation}

When the adherent cell monolayer was grown to about $80-90 \%$ confluency in the T75 flask, the serum-containing medium was discarded and cells were rinsed with phosphate-buffered saline (PBS) before the trypsinization $(0.25 \%(\mathrm{w} / \mathrm{v})$ trypsin, Thermo Fisher Scientific, Waltham, USA). Detached cells were suspended with Xeno-SFM and transferred to the shake flask for the cultivation and the shaking frequency was set at $130 \mathrm{rpm}$. During the period of the adaptation, the cells were refreshed or passaged with Xeno-SFM every 2 days to a seeding density of $1.0 \times 10^{6}$ cells $/ \mathrm{mL}$ until they could grow in single suspension with the minimal aggregation and a stable specific growth rate. The suspension cells were frozen with $10 \%$ $(\mathrm{v} / \mathrm{v})$ dimethyl sulfoxide to generate the cell bank after they were finally adapted to Xeno-SFM.

\section{Influenza virus infection}

The virus strain influenza A/Chicken/Guangdong/SS/94 (H9N2) was kindly supplied by Zhaoqing Dahuanong Biological Medicine Co., Ltd. and was initially grown in chicken embryos. The virus was adapted to the suspension MDCK cells over a series of virus passages with a low multiplicity of infection (MOI) of $10^{-3}$. Seed virus was stored at aliquots of $1 \mathrm{~mL}$ at $-80^{\circ} \mathrm{C}$. After the adaptation, the infectious titer of the final seed virus was $10^{8}$ $\mathrm{TCID}_{50} / \mathrm{mL}$.

Various medium exchange strategies were introduced in shake flasks at the time of infection (TOI) for process optimization. Infection was carried out either after a complete medium replacement at the viable cell concentration of $6 \times 10^{6}$ or $10 \times 10^{6}$ cells $/ \mathrm{mL}$ or after a $4: 5,3: 4$, $2: 3,1: 2,1: 3$ or $1: 4$ medium dilution at the cell concentration of $10-11 \times 10^{6}$ cells $/ \mathrm{mL}$. For example, with a $1: 2$ medium dilution, $25 \mathrm{~mL}$ fresh medium was added to the culture $(\mathrm{wv}=25 \mathrm{~mL})$ to reach a twofold increase in the working volume. Infection in bioreactors was performed with a 1:2 medium dilution at TOI. TPCK-trypsin (Sigma-Aldrich, Munich, Germany) was supplemented after medium exchange to a final concentration of $5 \mu \mathrm{g} /$ $\mathrm{mL}$. Diluted H9N2 seed virus was added with a MOI of $10^{-3}$.

\section{Virus quantification}

The hemagglutinin activity (HA) assay was used for the quantification of virus titer (Kalbfuss et al. 2008). The concentration of chicken erythrocyte solution (Shanghai Institute of Biological Products Co., Ltd, Shanghai, China) was set to $2 \times 10^{7}$ cells $/ \mathrm{mL}$ for determination. The virus titer was expressed as $\log _{2}(\mathrm{HAU} / 50 \mu \mathrm{L})$. Accordingly, the virus concentration $\left(C_{\mathrm{vir}, \max }\right.$, virions $\left./ \mathrm{mL}\right)$ was calculated by multiplying the HA titer and erythrocyte concentration as given by Eq. (1). The corresponding CSVY was calculated as given by Eq. (2):

$$
\begin{aligned}
& C_{v i r}=2 \times 10^{7} \times 2^{\log _{2}\left(\frac{\mathrm{HAU}}{50} \mu \mathrm{L}\right),} \\
& \mathrm{CSVY}=\frac{C_{\mathrm{vir}, \max } \times w v_{1}}{x_{\mathrm{v}, \max } \times w v_{2}},
\end{aligned}
$$

where $x_{\mathrm{v}, \max }$ represents the maximum viable cell concentration in the infection phase, $w v_{1}$ the working volume at highest viable cell concentration, and $w v_{2}$ the working volume at maximum virus titer.

\section{Transmission electron microscopy}

The virus supernatant was harvested from bioreactors and clarified by centrifugation at 10,000 rpm for $20 \mathrm{~min}$. The virus particles were purified by sucrose density gradient centrifugation using an ultracentrifuge (HITACHI, Tokyo, Japan) at 30,000 rpm for $2.5 \mathrm{~h}$ in a sucrose solution with a gradient density from 20 to $60 \%$. Transmission electron microscopy (TEM) of virus particles was performed using the negative staining method. The purified virion-containing solution was applied on a carbon-coated 230 mesh copper grids, stained with $2 \%$ phosphotungstic acid solution and viewed using the TEM (JEM-1400, Tokyo, JEOL).

\section{Vaccine preparation, immunization, and antibody determination}

The clarified H9N2 virus bulk produced in bioreactors was diluted to a final HA equal to the egg-derived H9N2 virus bulk. Subsequently the MDCK cell-derived virus bulk and egg-derived virus bulk were prepared into the corresponding oil emulsion inactivated vaccines. The 3-week-old specific pathogen-free (SPF) chickens were divided into two groups ( $n=10$ per group) and were subjected to subcutaneous injection on the neck with 
$0.3 \mathrm{~mL}$ MDCK cell-derived vaccine or egg-derived vaccine. At days 14, 21, and 28, blood samples were collected for serum separation. The procedure was approved by the Committee on the Ethics of Animal Experiments of Zhaoqing Dahuanong Biological Medicine Co., Ltd. The hemagglutination inhibition antibody titers of sera against the H9N2 virus derived from MDCK cells or eggs by one dose immunization were determined by hemagglutination inhibition (HI) assay (Pedersen 2008).

\section{Statistical analysis}

A $t$ test was used for statistical analysis using GraphPad Prism 7 software. The $p$ values lower than 0.05 (shown as the single asterisk in figures) were considered significant.

\section{Results and discussion}

\section{Adaptation of adherent MDCK cells to suspension culture}

For the cell adaptation to the suspension culture, a stepwise reduction of the serum and medium for adherent cells is the common approach. Nevertheless, in this work a direct adaptation of MDCK cell line to Xeno-SFM was attempted. Therefore, detached adherent MDCK cells were directly transferred to the shake flasks and cultivated in the Xeno-SFM. In the first stage of adaptation (0-9 days), the cell growth was unstable due to the direct removal of serum and the introduction of the new medium, with the cell growth rate ranging from 0.26 day $^{-1}$ to 0.65 day $^{-1}$ (Fig. 1b). This stage can be considered as a process of selecting the more "robust" cell population to achieve higher and stable cell growth. Despite the unstable cell growth, the viability of MDCK cells stayed above $90 \%$ in this stage (Fig. 1a). With the well-designed
Xeno-SFM, only a few small aggregates were observed in the culture in this stage (data not shown). In the second stage of adaptation (9-19 days), the cell aggregates disappeared and cells were growing in single suspension with a cell size of approximately $14 \mu \mathrm{m}$ (Fig. 4c, inset). In addition, the cell growth was stable with a growth rate of around 0.46 day $^{-1}$ and cell viability over $95 \%$ (Fig. 1). Therefore, over the whole cultivation, the adaptation seemed to have an obvious impact on the cell growth but not the overall cell viability, which was consistent with the previous study by Bissinger et al. (2019). Over multiple passages the fully adapted MDCK suspension cells were frozen to generate a cell bank for further studies.

Overall, the whole adaptation of the MDCK cells to the optimal cell growth was done in less than 3 weeks thanks to the Xeno-SFM which was directedly designed for the suspension culture. Compared to the adaptation process of some other reported established MDCK suspension cell lines with the step-wise approaches (over 40 passages) (Lohr et al. 2010; van Wielink et al. 2011), fast adaptation of MDCK cell line demonstrated in this work (10 passages) dramatically reduced the labor work. In addition, the thawing and long-term passages of the adapted cells in the Xeno-SFM confirmed the stable and fast cell growth (data not shown). Further genotyping and tumorigenicity studies of this MDCK cell line are needed as they are major concerns for the suspension cell lines for the potential commercial use.

\section{Cell growth and metabolism in batch cultivation}

Subsequently, the cell growth in batch cultivations using the fully adapted MDCK cells was evaluated in
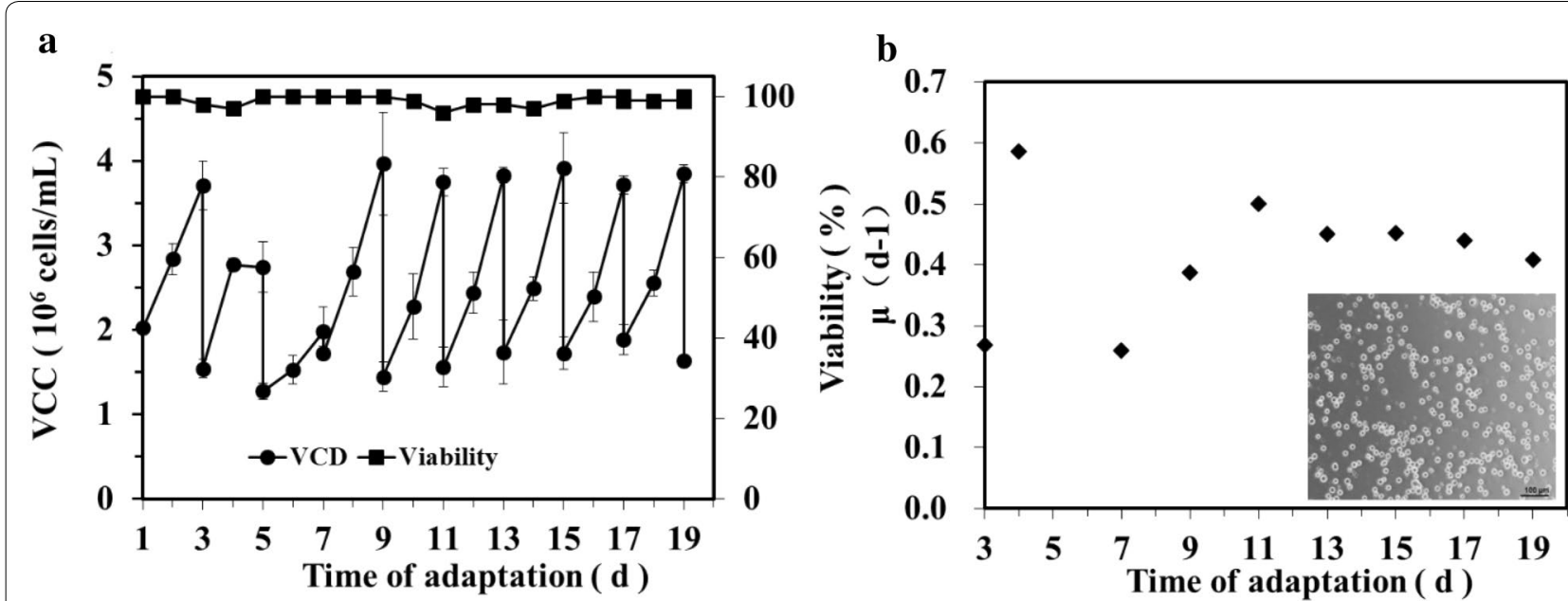

Fig. 1 Adaptation of adherent MDCK cells to suspension growth in Xeno serum-free medium. a Viable cell concentration (black circle) and cell viability (black square) over the period of adaptation. b Cell-specific growth rate (black diamond) of MDCK cells over the adaptation. The inset in the panel is a microscopy picture showing the morphology of the adapted suspension MDCK cells. Error bars represent the standard deviation of three analytical replicates 
the shake flasks. With a seeding density of $1.0 \times 10^{6}$ cells/mL, MDCK cells were able to grow to cell concentration up to $12 \times 10^{6}$ cells $/ \mathrm{mL}$ with a maximum cell-specific growth rate of $0.70 \mathrm{day}^{-1}$ (Fig. 2a and b). Additionally, the cell viability above $95 \%$ was observed in the exponential phase from $0 \mathrm{~h}$ to $72 \mathrm{~h}$ (Fig. 2a). Compared to the growth rates of other MDCK suspension cell lines reported by Lohr $\left(0.62\right.$ day $\left.^{-1}\right)$ (Lohr et al. 2010) and Huang $\left(0.73\right.$ day $\left.^{-1}\right)$ (Huang et al. 2015) as well as some other suspension cell lines used for the propagation of influenza virus regarding AGE1.CR cells $\left(0.67 \mathrm{~d}^{-1}\right)$ (Genzel et al. 2014), DuckCelt ${ }^{\circledR}-\mathrm{T} 17(0.6$ day $^{-1}$ ) (Petiot et al. 2018), and PBG.PK2.1 $\left(0.50\right.$ day $\left.^{-1}\right)$ (Granicher et al. 2019), this MDCK suspension cell line showed one of the highest growth rates. From 96 h, the cell concentration started to decrease combined with the decreasing cell viability as well as the negative growth rates.
The main metabolites in the shake flasks were measured over the whole batch cultivation as shown in Fig. 2c. The glucose and glutamine were depleted at $120 \mathrm{~h}$ when the viable cell concentration started to decrease. As two well-known by-products of cell culture, lactate and ammonium reached the concentrations up to $20 \mathrm{mmol} / \mathrm{L}$ and $4 \mathrm{mmol} / \mathrm{L}$, respectively, in the cell growth phase and these by-product levels do not show negative impacts on the cell growth for many animal cells (Cruz et al. 2000; Lao and Toth 1997; Ritter et al. 2010). From 72 h, lactate concentration started to decline when the glucose concentration was below $10 \mathrm{mmol} / \mathrm{L}$. This indicated a metabolic shift that MDCK cells started to uptake the lactate as the energy source instead of releasing the lactate when the glucose was about to limit. Overall, sufficient utilization of main energy substrates and moderate levels of byproduct production contributed to the high cell growth rate and high cell concentration of MDCK cells.
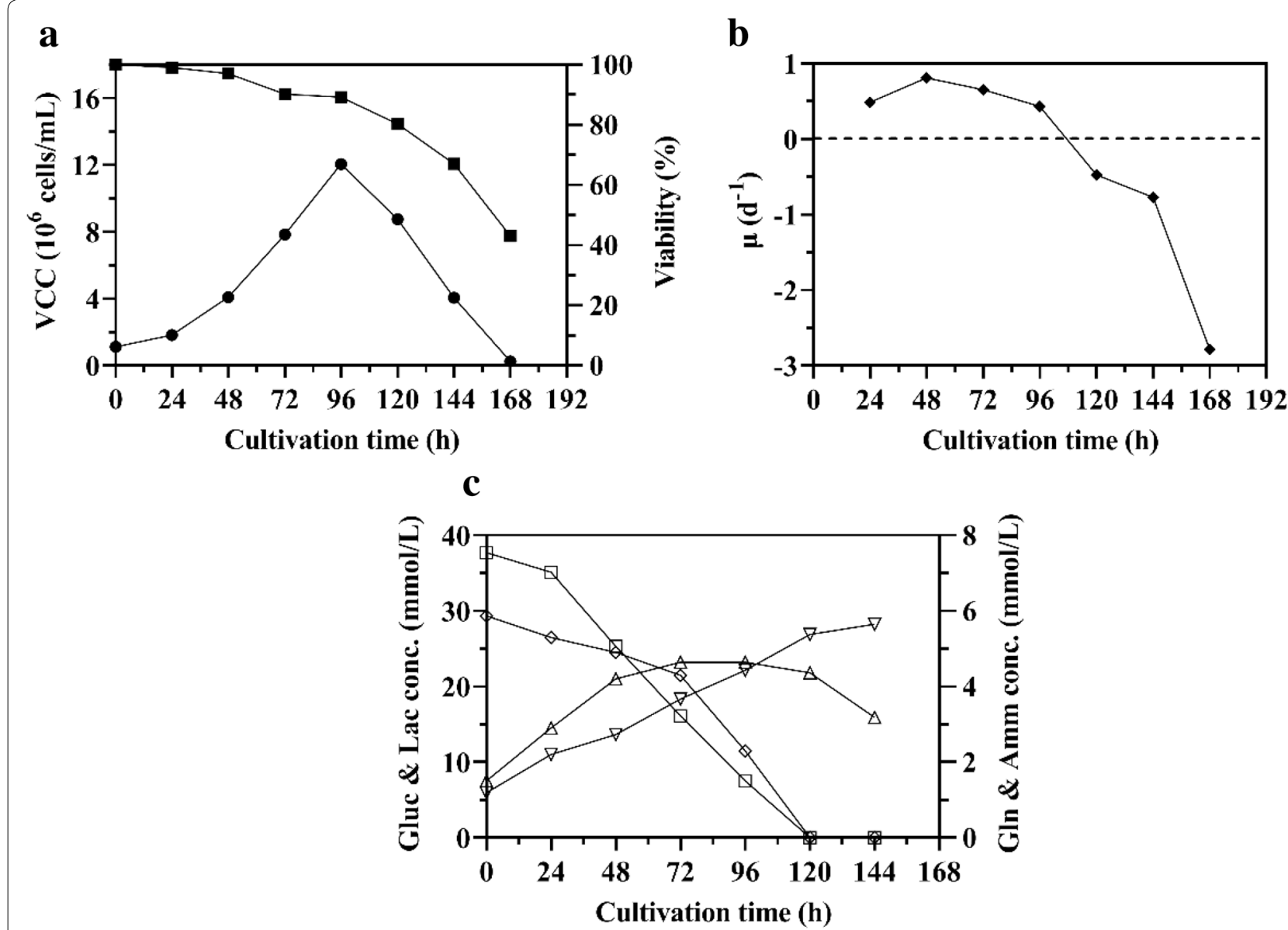

Fig. 2 Growth and metabolism of MDCK suspension cells in Xeno serum-free medium in shake flasks $(n=2)$. a Viable cell concentration (black circle) and cell viability (black square) over the batch cultivation. b Cell-specific growth rate (black diamond). c Concentrations of extracellular metabolites, including glucose (Gluc) (white square), glutamine (Gln) (white diamond), lactate (white triangle), and ammonium (Amm) (inverted white triangle), over the batch cultivation. The horizontal dashed line indicates the cell-specific growth rate of 0 day $^{-1}$ 
Medium exchange and the optimization of $\mathrm{MOI}$ for virus production

In the next step, the propagation of $\mathrm{H} 9 \mathrm{~N} 2$ virus in the MDCK suspension cells was evaluated and impacts of various infection strategies, including MOI and medium exchange on the virus production were investigated. To evaluate the impact of MOI on the virus titer, H9N2 seed virus, which has been adapted from eggs to adherent MDCK cells, was added to the culture with a MOI of $10^{-2}, 10^{-3}$, or $10^{-4}$ under various conditions (different cell concentrations at TOI and with or w/o medium exchange). The trypsin addition was optimized in the preliminary experiments and the final concentration of $5 \mu \mathrm{g} / \mathrm{mL}$ was used for virus production as the optimal condition (data not shown). With the higher MOI $\left(10^{-2}\right.$ and $\left.10^{-3}\right)$, similar infection dynamics and HA titers were obtained, where the HA accumulations were completed at $48 \mathrm{hpi}$ (Fig. 3). However, the lower MOI $\left(10^{-4}\right)$ led to the HA release with a delay of $24 \mathrm{~h}$ and lower maximum HA titers compared to the experiments performed with MOI of $10^{-2}$ and $10^{-3}$ (Fig. 3). As a critical parameter for the virus infection, the selection of the optimal MOI for the virus production process needs to be taken into account. As the virus particles in the medium are transported to the target cells by diffusion, using higher MOI can increase the chance of viruses to attach and enter the cells, but lower MOI can reduce the occurrence of defective interfering particles which was described previously
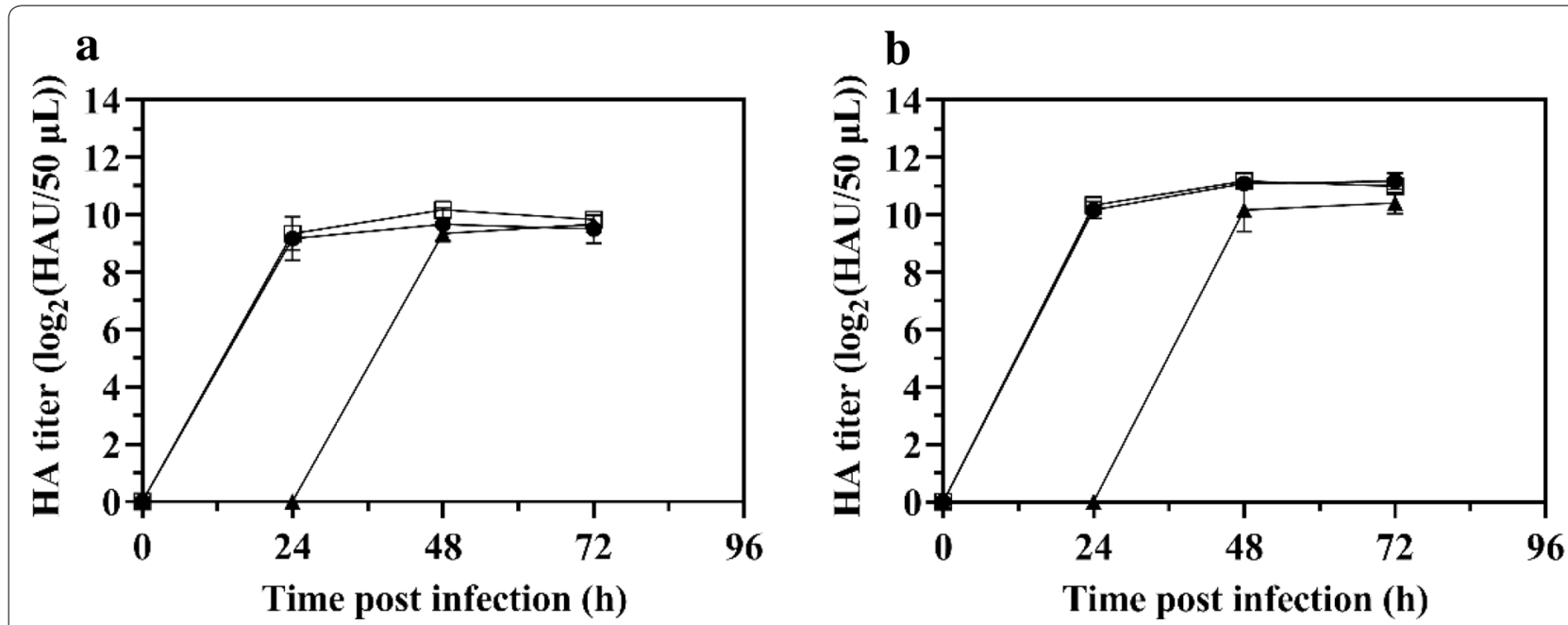

C

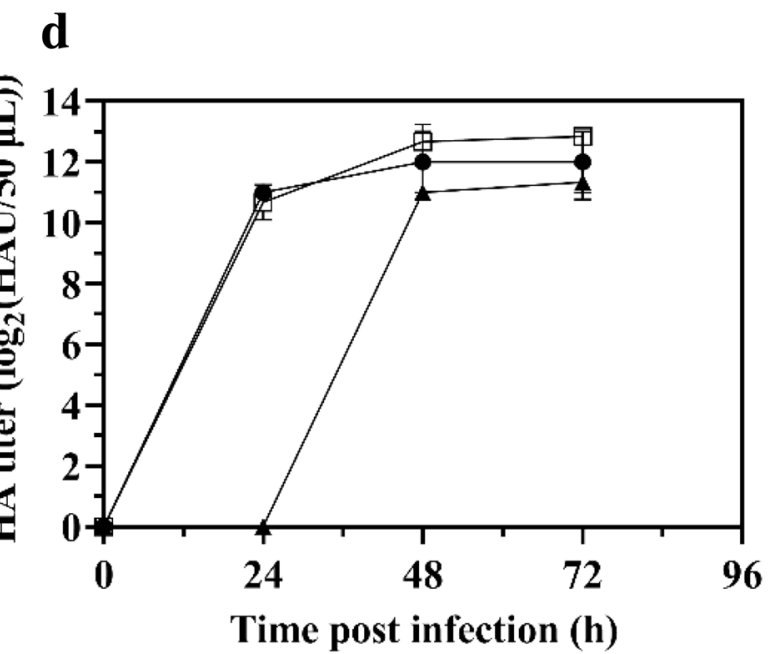

Fig. 3 Optimization of infection parameters for H9N2 production in Xeno serum-free medium in shake flasks ( $n=3$ ). HA titers were shown in different panels when cells were infected at cell concentration of $6 \times 10^{6}$ cells $/ \mathrm{mL}$ or $10 \times 10^{6}$ cells $/ \mathrm{mL}$ with or without the medium exchange at TOI with a MOl of $10^{-2}$ (black circle), $10^{-3}$ (white square) and $10^{-4}$ (black triangle). a Cell concentration of $6 \times 10^{6} \mathrm{cells} / \mathrm{mL}$ without medium exchange. b Cell concentration of $6 \times 10^{6}$ cells $/ \mathrm{mL}$ with medium exchange. c Cell concentration of $10 \times 10^{6}$ cells $/ \mathrm{mL}$ without medium exchange. $\mathbf{d}$ Cell concentration of $10 \times 10^{6}$ cells $/ \mathrm{mL}$ with medium exchange 
to interfere with the propagation of intact particles and decrease the virus titer (Frensing et al. 2013). In this work, the MOI of $10^{-2}$ and $10^{-3}$ contributed to similar virus titers and the MOIs are also in a comparable range as the optimal MOI reported previously for other cell lines (Genzel et al. 2010; Le Ru et al. 2010; Li et al. 2018).

The medium exchange was introduced at TOI when cell concentrations were $6 \times 10^{6}$ and $10 \times 10^{6}$ cells $/ \mathrm{mL}$ to evaluate its impact on improving the virus titer. For the experiments where cells were infected at cell concentration of $6 \times 10^{6}$ cells $/ \mathrm{mL}$ at TOI, a maximum HA titer of $11.17 \log _{2}(\mathrm{HAU} / 50 \mu \mathrm{L})$ was obtained with medium exchange performed at TOI (MOI 0.001) compared to $10.17 \log _{2}(\mathrm{HAU} / 50 \mu \mathrm{L})$ obtained without medium exchange (MOI 0.001) (Fig. 3a and b). For the experiments using $10 \times 10^{6}$ cells $/ \mathrm{mL}$, a very low maximum HA titer of only $4 \log _{2}(\mathrm{HAU} / 50 \mu \mathrm{L})$ was determined without the medium exchange (MOI 0.01), while a drastic increase in HA titer to $12.67 \log _{2}(\mathrm{HAU} / 50 \mu \mathrm{L})$ was obtained after the medium exchange (MOI 0.001) (Fig. 3c and $\mathrm{d}$ ). It is clear that medium renewal in the infection phase had an impact on virus titer and HA titers were increased after medium exchange most likely due to the supply of medium substrates and removal of accumulated by-products. This was also confirmed in a previous study using adherent MDCK cells and rational substrate supply was necessary in the infection phase to improve the virus titer as higher demand of substrates was needed by the infected cells to produce viruses (Huang et al. 2014). Accordingly, the maximum CSVYs calculated from HA titers with medium exchange at TOI (6955 virions/cell for $6 \times 10^{6}$ cells $/ \mathrm{mL}$ and 12,556 virions/cell for $10 \times 10^{6}$ cells $/ \mathrm{mL}$ ) was higher than that without medium exchange (3690 virions/cell for $6 \times 10^{6}$ cells $/ \mathrm{mL}$ and 30 virions/cell for $10 \times 10^{6}$ cells $/ \mathrm{mL}$ ), respectively, which indicated that the "cell density effect" described above was improved.

\section{Various feed strategies for virus production}

In the last section, higher virus titer $\left(12.75 \log _{2}\right.$ (HAU/50 $\mu \mathrm{L})$ ) was achieved with medium exchange at TOI at higher cell concentration of $10 \times 10^{6}$ cells $/ \mathrm{mL}$. However, for suspension cells, complete medium exchange would not be favored in large-scale vaccine manufacturing due to its complex operation and long operation duration. The feed strategy considering the medium dilution and culture volume expansion can be an option. Therefore, cultivations in shake flasks using various medium dilution strategies at TOI were performed with the optimal MOI of $10^{-3}$ and trypsin addition to a final concentration of $5 \mu \mathrm{g} / \mathrm{mL}$ to simplify the process and to improve the HA titer. At TOI, a fourfold, threefold, twofold, 1.5fold, 4/3-fold, or 1.25-fold working volume expansion was conducted by adding the fresh Xeno-SFM when the cells grew to approximately $10 \times 10^{6}$ cells $/ \mathrm{mL}$ before the virus and trypsin addition. As shown in Fig. 4a, the various dilution ratios at TOI resulted in a decrease in the cell concentration in a range of $2.6-8.5 \times 10^{6}$ cells $/ \mathrm{mL}$, followed by a continued growth for the first $24 \mathrm{hpi}$. The highest cell concentrations were observed at $24 \mathrm{hpi}$ and subsequently cells started to die. In contrast to no titer measured in the control experiment without medium exchange, all the medium dilution strategies led to significantly higher HA titers and the maximum HA titers were obtained at $48 \mathrm{hpi}$ (Fig. 4b). Using the 1:2 medium dilution strategy, the highest HA titer of $13 \log _{2}$ (HAU/50 $\mu \mathrm{L}$ ) was obtained compared to the HA titers of $10.75,11$, 12,12 , and $12 \log _{2}(\mathrm{HAU} / 50 \mu \mathrm{L})$ for the experiments with 1:4, 1:3, 2:3, 3:4, and 4:5 dilution, respectively (Fig. 4b). The highest titer was also similar to the titer obtained with total medium exchange. Considering the CSVY, the 1:2 dilution strategy also showed the highest value of 18,104 virions/cell compared to other dilution strategies (Fig. 4c). Medium dilution strategies led to the partial renewal of substrates and dilution of inhibitors in the culture, which is advantageous for the virus replication and packaging. Therefore, the medium supplement was applied in the infection phase for virus production in some works of literature to achieve higher virus productivity and to ease the operation in bioreactors for suspension culture (Granicher et al. 2019; Peschel et al. 2013; Wang et al. 2017). Additionally, using the medium dilution strategy, it is critical to find the balance between the cell concentration and the substrate supply, in which the 1:2 medium dilution strategy appeared to be optimal in this work.

\section{Bioreactor evaluation}

Cultivations in lab-scale bioreactors for H9N2 virus production were evaluated compared to shake flasks using the optimized conditions regarding the MOI of $10^{-3}$, trypsin addition to a final concentration of $5 \mu \mathrm{g} / \mathrm{mL}$ and 1:2 medium dilution at TOI. With a seeding cell concentration at $1 \times 10^{6}$ cells $/ \mathrm{mL}$, slightly higher cell concentration up to $9.7 \times 10^{6}$ cells $/ \mathrm{mL}$ was reached in the bioreactors at $72 \mathrm{~h}$ compared to shake flasks $\left(8.1 \times 10^{6}\right.$ cells $/ \mathrm{mL}$ ) possibly due to more stable control of process parameters in bioreactors (Fig. 5a). Comparable high viabilities over $96 \%$ were observed both in bioreactors and shake flasks during the cell growth phase (Fig. 5a). After infection, cells continued to grow to maximum cell concentrations of approximately $7 \times 10^{6}$ cells $/ \mathrm{mL}$ at 24 hpi and started to die with the onset of virus accumulation both in bioreactors and shake flasks. Comparable virus infection dynamics regarding the HA was observed, where at $48 \mathrm{hpi}$ both infections showed the maximum virus titer of $12.17 \log _{2}(\mathrm{HAU} / 50 \mu \mathrm{L})$ for the bioreactors 

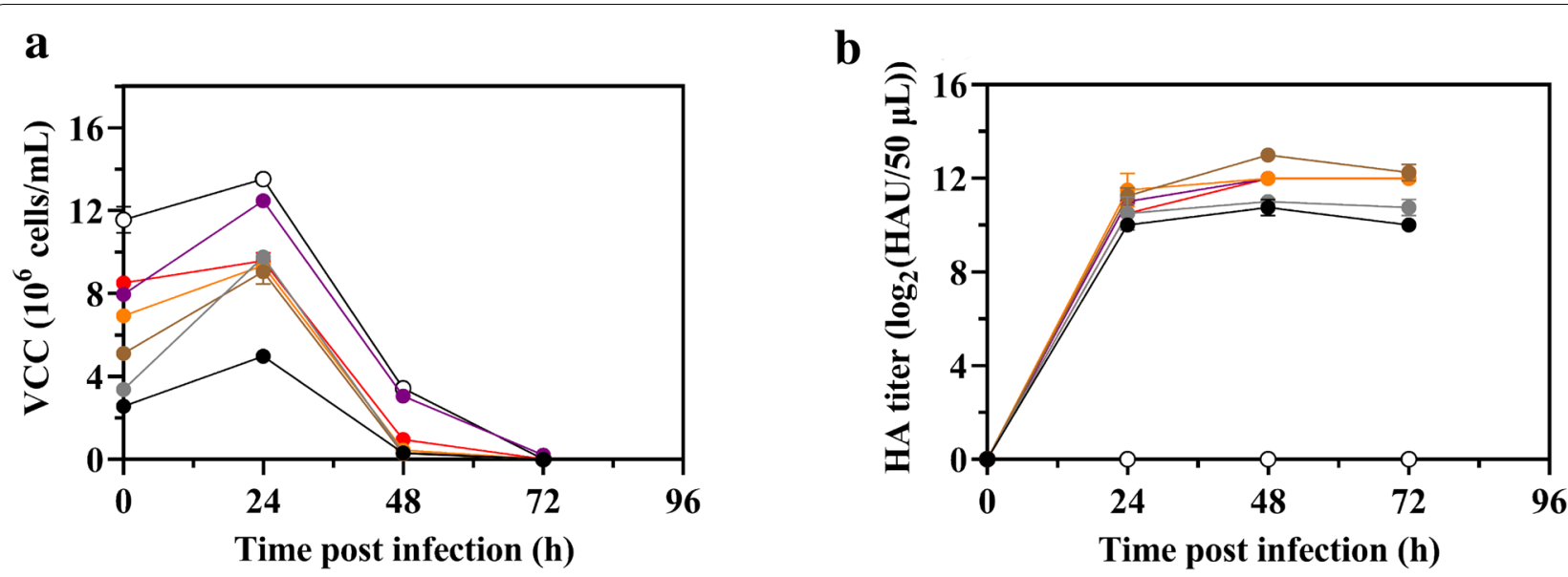

c

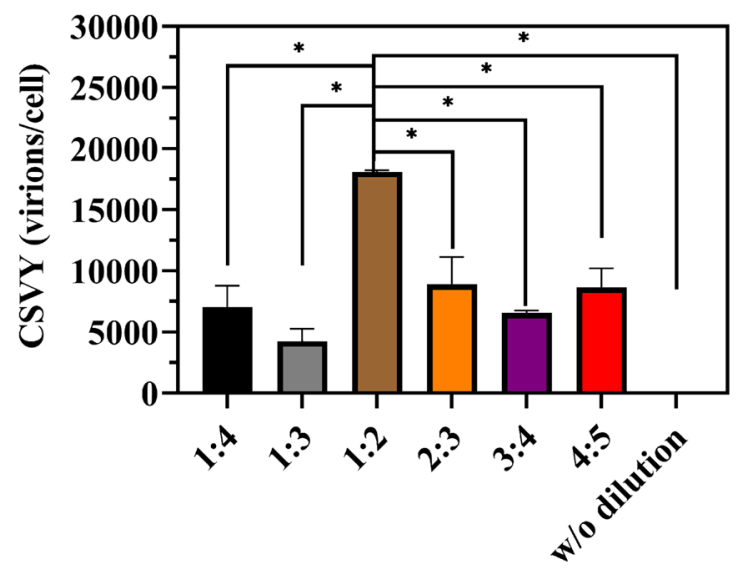

Fig. 4 MDCK cell growth and H9N2 virus production with various feed strategies at TOI in shake flasks $(n=3)$. a Cell growth in the infection phase. b HA titers in the infection phase. c The corresponding cell-specific virus yield. Medium dilution: 1:4 (black), 1:3 (gray), 1:2 (brown), 2:3 (orange), 3:4 (purple), 4:5 (red), and w/o dilution (white)

and $12.33 \log _{2}(\mathrm{HAU} / 50 \mu \mathrm{L})$ for the shake flasks (Fig. 5b). Based on the similar maximum cell concentrations during the infection phase and similar virus titers, comparable CSVYs (13,151 virions/cell for bioreactors and 14,465 virions/cell for shake flasks) were measured and this indicated that the process has the potential to be scalable to higher bioreactor volumes (Fig. 5c). In addition, the inset of a TEM picture of the purified H9N2 viruses produced in the bioreactor showed that the particles were spherical and with intact membranous structures (Fig. 5c). Although higher virus titers were achieved by using complex approaches in some works of literature, the HA titer of $12.50 \log _{2}(\mathrm{HAU} / 50 \mu \mathrm{L})$ achieved in this work using MDCK suspension cells was the highest in simple batch cultivations in the bioreactors (Genzel et al. 2014; Nikolay et al. 2020; Tapia et al. 2016). Furthermore, this was also the highest HA titer reported for the H9N2 virus production in animal cell culture so far (Li et al. 2009; Ren et al. 2015; Wang et al. 2017). The high
HA titer was attributed to the combination of high cell concentration and high CSVY. With this advantage, the MDCK cell-based process by using simple and efficient cultivation would be favored for the production of veterinary vaccines and is promising to be an alternative for the conventional egg-based platform, particularly in the case of a pandemic.

Immunogenicity of the MDCK cell-derived H9N2 vaccines The virus supernatant produced in the bioreactor at 48 hpi and 72 hpi was harvested, clarified, and prepared into the inactivated vaccines according to the standard preparation protocol. The SPF chicken of 3 weeks old were vaccinated with $0.3 \mathrm{~mL}$ of MDCK-derived $\mathrm{H} 9 \mathrm{~N} 2$ vaccine or egg-derived H9N2 vaccine. Chicken blood was collected on day 14, 21, and 28 for $\mathrm{HI}$ assay to evaluate the immunogenicity of the vaccines. In general, the chickens immunized with MDCK-derived H9N2 vaccines or eggderived H9N2 vaccine showed comparable $\mathrm{HI}$ antibody 

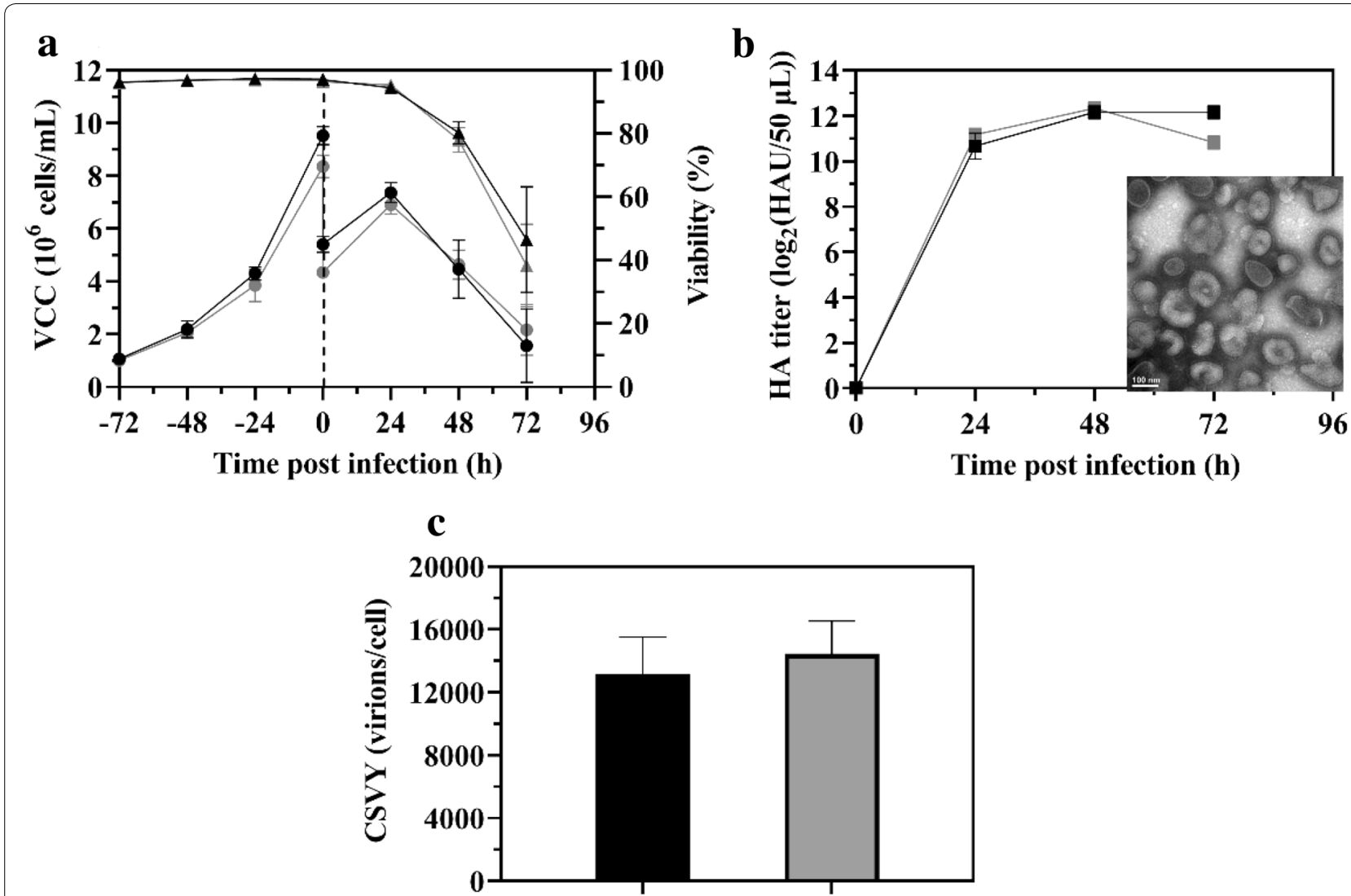

Bioreactors Shake flasks

Fig. 5 MDCK cell growth and H9N2 virus production in stirred tank bioreactors $(n=3)$ and shake flasks $(n=3)$. a Viable cell concentration (black circle) and cell viability (black triangle) of MDCK cells in bioreactors (black) and shake flasks (gray). b HA titers of viruses produced by MDCK cells in bioreactors (black) and shake flasks (gray). The inset in the panel is a TEM picture of purified viruses harvested from one of the bioreactors. $\mathbf{c}$ The calculated cell-specific virus yield of the viruses in bioreactors (black column) and shake flasks (gray column)

titers. High $\mathrm{HI}$ antibody titers of $6.9 \log _{2}(\mathrm{HAU} / 50 \mu \mathrm{L})$ for MDCK-derived vaccine and $5.7 \log _{2}(\mathrm{HAU} / 50 \mu \mathrm{L})$ for egg-derived vaccine were detected in the chicken serum on day 14 (Fig. 6). The chickens showed the highest $\mathrm{HI}$ antibody titers against both types of vaccines on day 21 and the titers were stable afterward. Furthermore, HI antibody titer of $8.6 \log _{2}(\mathrm{HAU} / 50 \mu \mathrm{L})$ was obtained against the MDCK-derived vaccine prepared from the virus harvested at $48 \mathrm{hpi}$, similar to that harvested at 72 hpi $\left(9.4 \log _{2}(\mathrm{HAU} / 50 \mu \mathrm{L})\right)$ (Fig. 6). This indicated the harvest time seemed not to have an impact on the immunogenicity of MDCK-derived vaccines. Overall, the MDCK cell-derived H9N2 vaccines effectively induced the immune response regarding the H9N2-specific antibodies and this revealed that MDCK cell-derived H9N2 vaccine can be an alternative for the egg-derived vaccines to protect chickens from the H9 infection. Further studies considering the challenge assays with the H9N2 virus strain should be followed to evaluate the protective efficacy of the vaccine. Additionally, the safety of the vaccine

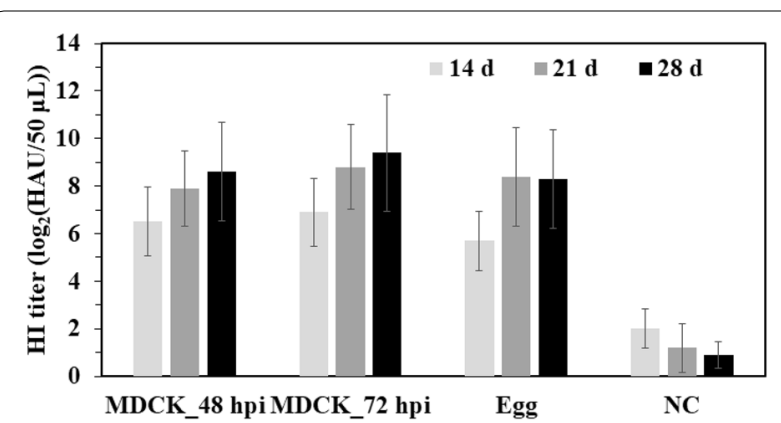

Fig. 6 Immunogenicity of the MDCK cell-derived H9N2 vaccines compared to egg-derived vaccines. The inactivated MDCK cell-derived H9N2 vaccines prepared by the virus harvested at $48 \mathrm{hpi}$ or $72 \mathrm{hpi}$ and inactivated egg-derived $\mathrm{H} 9 \mathrm{~N} 2$ vaccines were injected to 3-week-old SPF chickens. HI activity of chicken serum against H9N2 vaccines collected on day 14 (light gray column), day 21 (dark gray column), and day 28 (black column) was determined 
regarding its impact on the health and growth of vaccinated chickens should be evaluated as well.

\section{Conclusion}

Advances in the medium development facilitate an easier and efficient cell adaptation to growth in suspension, and for the first time, a fast adaptation of an adherent MDCK cell line to grow in single suspension in a serumfree medium after only 19 days was demonstrated. The resulting adapted MDCK cells were able to show the good growth performance of high cell concentration up to $12 \times 10^{6}$ cells $/ \mathrm{mL}$ in batch cultures. The optimization of infection conditions and the implementation of $1: 2$ medium dilution strategy at TOI allowed the improved HA titer. Particularly, 1:2 medium dilution strategy is suitable to be applied in large-scale manufacturing of influenza vaccines as it can ease the operation and expand the culture volume for infection. With the optimized operating conditions, lab-scale bioreactor cultivations resulted in the highest virus titer of $12.50 \log _{2}(\mathrm{HAU} / 50$ $\mu \mathrm{L}$ ) and the highest CSVY over 14,000 virions/cell reported for bioreactor process using MDCK cells in batch cultivations. The high $\mathrm{HI}$ antibody titers elicited by chickens immunized by the MDCK cell-derived H9N2 vaccine demonstrated the high immunogenicity of the vaccine. Further studies including the tumorigenicity of suspension MDCK cell line and the safety of the H9N2 vaccine for poultry should be planned, and therefore, the use of MDCK suspension cell line for the production of human influenza seasonal or pandemic vaccines could be anticipated. Overall, the platform established in this work can be competitive to alternate the egg-based production systems for efficient influenza vaccine manufacturing.

\section{Abbreviations \\ MDCK: Mardin-Darby canine kidney; AIV: Avian influenza virus; CSVY: Cell- specific virus yield; DMEM: Dulbecco's modified Eagle's medium; DO: Dissolved oxygen; PBS: Phosphate-buffered saline; SFM: Serum-free medium; MOI: Mul- tiplicity of infection; TOI:Time of infection; HA: Hemagglutinin activity; TEM: Transmission electron microscopy; SPF: Specific pathogen free; $\mathrm{HI}$ : Hemag- glutination inhibition.}

\section{Acknowledgements}

This work was financially supported by the Fundamental Research Funds for the Central Universities (No. 22221818014) and the Development Funds of Shanghai Zhangjiang National Independent Innovation Demonstration Zone (No. ZJ2015-ZD-002).

\section{Authors' contributions}

$\mathrm{YW}, \mathrm{HJ}, \mathrm{HL}, \mathrm{XL}$, and $\mathrm{W}$-ST conceived and designed this study. YW and $\mathrm{HJ}$ performed the experiments. YW, HJ, HL, and XL analyzed the data. YW wrote the manuscript. All authors read and approved the final manuscript.

\section{Funding}

Not applicable.
Availability of data and material

The data that support the findings of this study are available from the corresponding author upon reasonable request.

\section{Ethics approval consent to participate}

The chicken study protocol was approved by the Committee on the Ethics of Animal Experiments of Zhaoqing Dahuanong Biological Medicine Co., Ltd.

\section{Consent for publication}

All the authors have read and approved the manuscript before the submission to bioresources and bioprocessing.

\section{Competing interests}

The authors declare that they have no competing interests.

\section{Author details}

${ }^{1}$ State Key Laboratory of Bioreactor Engineering, East China University of Science and Technology, 130 Meilong Road, P. O. Box 309\#, Shanghai 200237, China. ${ }^{2}$ Key Laboratory of Biotechnology and Bioproducts Development for Animal Epidemic Prevention, Ministry of Agriculture, P. R. China, Guangdong Wens Dahuanong Biotechnology Co., Ltd, No. 6 Dongdi North Road, Xincheng Town, Xinxing County, Yunfu 527400, China. ${ }^{3}$ Guangdong Enterprise Key Laboratory of Biotechnology R \& D of Veterinary Biological Products, Zhaoqing Dahuanong Biological Medicine Co., Ltd., Zhaoqing High-Tech Development Zone, Zhaoqing 526238, Guangdong Province, China. ${ }^{4}$ Shanghai BioEngine Sci-Tech Co., Ltd, 781 Cailun Road, Shanghai 201203, China.

Received: 27 August 2020 Accepted: 26 November 2020

Published online: 02 December 2020

\section{References}

Bissinger T, Fritsch J, Mihut A, Wu Y, Liu X, Genzel Y, Tan W-S, Reichl U (2019) Semi-perfusion cultures of suspension MDCK cells enable high cell concentrations and efficient influenza A virus production. Vaccine 37(47):7003-7010. https://doi.org/10.1016/j.vaccine.2019.04.054

Bock A, Sann H, Schulze-Horsel J, Genzel Y, Reichl U, Mohler L (2009) Growth behavior of number distributed adherent MDCK cells for optimization in microcarrier cultures. Biotechnol Prog 25(6):1717-1731. https://doi. org/10.1002/btpr.262

Brown SW, Mehtali M (2010) The Avian EB66 ${ }^{\circledR}$ cell line, application to vaccines, and therapeutic protein production. PDA J Pharm Sci Technol 64(5):419

Chu C, Lugovtsev V, Golding H, Betenbaugh M, Shiloach J (2009) Conversion of MDCK cell line to suspension culture by transfecting with human siat7e gene and its application for influenza virus production. PNAS 106(35):14802-14807. https://doi.org/10.1073/pnas.0905912106

Coronel J, Behrendt I, Burgin T, Anderlei T, Sandig V, Reichl U, Genzel Y (2019) Influenza A virus production in a single-use orbital shaken bioreactor with ATF or TFF perfusion systems. Vaccine 37(47):7011-7018. https://doi. org/10.1016/j.vaccine.2019.06.005

Cruz HJ, Freitas CM, Alves PM, Moreira JL, Carrondo MJT (2000) Effects of ammonia and lactate on growth, metabolism, and productivity of BHK cells. Enzyme Microbial Technol 27(1):43-52. https://doi.org/10.1016/ S0141-0229(00)00151-4

Frensing T, Heldt FS, Pflugmacher A, Behrendt I, Jordan I, Flockerzi D, Genzel Y, Reichl U (2013) Continuous influenza virus production in cell culture shows a periodic accumulation of defective interfering particles. PLoS ONE 8(9):e72288. https://doi.org/10.1371/journal.pone.0072288

Gao M, Cao C, Ma H, Zhu C, Jia Q (2016) Comparative study of two kinds of cell counting methods in cytotoxicity test. J Med Pest Control 32(12):1313-1316

Genzel Y, Reichl U (2009) Continuous cell lines as a production system for influenza vaccines. Expert Rev Vaccines 8(12):1681-1692

Genzel Y, Olmer RM, Schafer B, Reichl U (2006) Wave microcarrier cultivation of MDCK cells for influenza virus production in serum containing and serum-free media. Vaccine 24(35-36):6074-6087. https://doi. org/10.1016/j.vaccine.2006.05.023

Genzel Y, Dietzsch C, Rapp E, Schwarzer J, Reichl U (2010) MDCK and Vero cells for influenza virus vaccine production: a one-to-one comparison up to 
lab-scale bioreactor cultivation. Appl Microbiol Biotechnol 88(2):461-475. https://doi.org/10.1007/s00253-010-2742-9

Genzel Y, Vogel T, Buck J, Behrendt I, Ramirez DV, Schiedner G, Jordan I, Reichl U (2014) High cell density cultivations by alternating tangential flow (ATF) perfusion for influenza A virus production using suspension cells. Vaccine 32(24):2770-2781. https://doi.org/10.1016/j.vaccine.2014.02.016

Granicher G, Coronel J, Pralow A, Marichal-Gallardo P, Wolff M, Rapp E, Karlas A, Sandig V, Genzel Y, Reichl U (2019) Efficient influenza A virus production in high cell density using the novel porcine suspension cell line PBG.PK2.1. Vaccine 37(47):7019-7028. https://doi.org/10.1016/j.vacci ne.2019.04.030

Gu M, Xu L, Wang X, Liu X (2017) Current situation of H9N2 subtype avian influenza in China. Vet Res 48(1):49. https://doi.org/10.1186/s1356 7-017-0453-2

Harding AT, Heaton NS (2018) Efforts to improve the seasonal influenza vaccine. Vaccines. https://doi.org/10.3390/vaccines6020019

Hegde NR (2015) Cell culture-based influenza vaccines: a necessary and indispensable investment for the future. Hum Vaccin Immunother 11(5):12231234. https://doi.org/10.1080/21645515.2015.1016666

Hu AY, Weng TC, Tseng YF, Chen YS, Wu CH, Hsiao S, Chou AH, Chao HJ, Gu A, Wu SC, Chong P, Lee MS (2008) Microcarrier-based MDCK cell culture system for the production of influenza H5N1 vaccines. Vaccine 26(45):57365740. https://doi.org/10.1016/j.vaccine.2008.08.015

Huang D, Zhao L, Tan W (2011) Adherent and single-cell suspension culture of Madin-Darby canine kidney cells in serum-free medium. Chin J Biotechnol/Shengwu Gongcheng Xuebao 27:645-652

Huang D, Xia-Hou K, Liu X-P, Zhao L, Fan L, Ye Z, Tan W-S, Luo J, Chen Z (2014) Rational design of medium supplementation strategy for improved influenza viruses production based on analyzing nutritional requirements of MDCK Cells. Vaccine 32:7091-7097. https://doi.org/10.1016/j.vacci ne.2014.10.067

Huang D, Peng WJ, Ye Q, Liu XP, Zhao L, Fan L, Xia-Hou K, Jia HJ, Luo J, Zhou LT, Li BB, Wang SL, Xu WT, Chen Z, Tan WS (2015) Serum-free suspension culture of MDCK cells for production of influenza H1N1 vaccines. PLoS ONE 10(11):e0141686. https://doi.org/10.1371/journal.pone.0141686

Hussain Al, Cordeiro M, Sevilla E, Liu J (2010) Comparison of egg and high yielding MDCK cell-derived live attenuated influenza virus for commercial production of trivalent influenza vaccine: in vitro cell susceptibility and influenza virus replication kinetics in permissive and semi-permissive cells. Vaccine 28(22):3848-3855. https://doi.org/10.1016/j.vacci ne.2010.03.005

Kalbfuss B, Knöchlein A, Kröber T, Reichl U (2008) Monitoring influenza virus content in vaccine production: precise assays for the quantitation of hemagglutination and neuraminidase activity. Biologicals 36(3):145-161. https://doi.org/10.1016/j.biologicals.2007.10.002

Lamb RA, Takeda M (2001) Death by influenza virus protein. Nat Med 7(12):1286-1288. https://doi.org/10.1038/nm1201-1286

Lao M-S, Toth D (1997) Effects of ammonium and lactate on growth and metabolism of a recombinant Chinese Hamster ovary cell culture. Biotechnol Prog 13(5):688-691. https://doi.org/10.1021/bp9602360

Le Ru A, Jacob D, Transfiguracion J, Ansorge S, Henry O, Kamen AA (2010) Scalable production of influenza virus in HEK-293 cells for efficient vaccine manufacturing. Vaccine 28(21):3661-3671. https://doi.org/10.1016/j.vacci ne.2010.03.029

Lee D-H, Song C-S (2013) H9N2 avian influenza virus in Korea: evolution and vaccination. Clin Exp Vaccine Res 2(1):26-33. https://doi.org/10.7774/ cevr.2013.2.1.26

Li C, Xiao J, Li X, Liu D (2009) Research on multiplication of the H9N2 subtype avian influenza virus in large-scale microcarrier-based MDCK cell culture system. Chin J Zoonoses 25(12):1149-1153

Li X, Shi J, Guo J, Deng G, Zhang Q, Wang J, He X, Wang K, Chen J, Li Y, Fan J, Kong H, Gu C, Guan Y, Suzuki Y, Kawaoka Y, Liu L, Jiang Y, Tian G, Li Y, Bu Z, Chen $\mathrm{H}$ (2014) Genetics, receptor binding property, and transmissibility in mammals of naturally isolated H9N2 Avian Influenza viruses. PLoS Pathog 10(11):e1004508-e1004508. https://doi.org/10.1371/journal.ppat.10045 08

Li L, Du X, Zhang L, Yang L, Gao X, Tang D, Zhao H, Jiang X, Zhang T, Li J (2018) Optimization of cultivation conditions for reassortant Avian Influenza virus. Sci Agric Sinica 51(17):3415-3426. https://doi.org/10.3864/j. issn.0578-1752.2018.17.016
Lohr V, Rath A, Genzel Y, Jordan I, Sandig V, Reichl U (2009) New avian suspension cell lines provide production of influenza virus and MVA in serum-free media: studies on growth, metabolism and virus propagation. Vaccine 27(36):4975-4982. https://doi.org/10.1016/j.vaccine.2009.05.083

Lohr V, Genzel Y, Behrendt I, Scharfenberg K, Reichl U (2010) A new MDCK suspension line cultivated in a fully defined medium in stirred-tank and wave bioreactor. Vaccine 28(38):6256-6264. https://doi.org/10.1016/j. vaccine.2010.07.004

Maranga L, Brazao TF, Carrondo MJ (2003) Virus-like particle production at low multiplicities of infection with the baculovirus insect cell system. Biotechnol Bioeng 84(2):245-253. https://doi.org/10.1002/bit.10773

Milian E, Kamen AA (2015) Current and emerging cell culture manufacturing technologies for influenza vaccines. Biomed Res Int. https://doi. org/10.1155/2015/504831

Nikolay A, Bissinger T, Gränicher G, Wu Y, Genzel Y, Reichl U (2020) Perfusion control for high cell density cultivation and viral vaccine production. In: Pörtner R (ed) Animal cell biotechnology: methods and protocols. Springer, New York, pp 141-168

Park K, Kwon H-I, Song M-S, Pascua PN, Baek Y, Lee JH, Jang H-L, Lim J-Y, Mo I-P, Moon H, Kim C-J, Choi YK (2011) Rapid evolution of low-pathogenic H9N2 avian influenza viruses following poultry vaccination programmes. J Gen Virol 92:36-50. https://doi.org/10.1099/vir.0.024992-0

Pau MG, Ophorst C, Koldijk MH, Schouten G, Mehtali M, Uytdehaag F (2001) The human cell line PER.C6 provides a new manufacturing system for the production of influenza vaccines. Vaccine. 19(17):2716-2721. https://doi. org/10.1016/S0264-410X(00)00508-9

Pedersen JC (2008) Hemagglutination-inhibition test for Avian Influenza virus subtype identification and the detection and quantitation of serum antibodies to the Avian Influenza virus. In: Spackman E (ed) Avian Influenza virus. Humana Press, Totowa, pp 53-66

Peschel B, Frentzel S, Laske T, Genzel Y, Reichl U (2013) Comparison of influenza virus yields and apoptosis-induction in an adherent and a suspension MDCK cell line. Vaccine 31(48):5693-5699. https://doi.org/10.1016/j.vacci ne.2013.09.051

Petiot E, Proust A, Traversier A, Durous L, Dappozze F, Gras M, Guillard C, Balloul JM, Rosa-Calatrava M (2018) Influenza viruses production: evaluation of a novel avian cell line DuckCelt(R)-T17. Vaccine 36(22):3101-3111. https:// doi.org/10.1016/j.vaccine.2017.03.102

Pu J, Wang S, Yin Y, Zhang G, Carter R, Wang J, Xu G, Sun H, Wang M, Wen C, Wei Y, Wang D, Zhu B, Lemmon G, Jiao Y, Duan S, Wang Q, Du Q, Sun M, Webster R (2015) Evolution of the H9N2 influenza genotype that facilitated the genesis of the novel H7N9 virus. Proc Natl Acad Sci USA 112:548-553. https://doi.org/10.1073/pnas.1422456112

Pu J, Sun H, Qu Y, Wang C, Gao W, Zhu J, Sun Y, Bi Y, Huang Y, Chang K-C, Cui J, Liu J (2017) M gene reassortment in H9N2 Influenza Virus promotes early infection and replication: contribution to rising virus prevalence in chickens in China. J Virol. https://doi.org/10.1128/jvi.02055-16

Ren Z, Lu Z, Wang L, Huo Z, Cui J, Zheng T, Dai Q, Chen C, Qin M, Chen M, Yang $R$ (2015) Rapid production of a H9N2 influenza vaccine from MDCK cells for protecting chicken against influenza virus infection. Appl Microbiol Biotechnol 99(7):2999-3013. https://doi.org/10.1007/s00253-015-6406-7

Ritter JB, Wahl AS, Freund S, Genzel Y, Reichl U (2010) Metabolic effects of influenza virus infection in cultured animal cells: intra- and extracellular metabolite profiling. BMC Syst Biol 4(61):1-22. https://doi. org/10.1186/1752-0509-4-61

Sorrell E, Wan H, Araya Y, Song H, Perez D (2009) Minimal molecular constraints for respiratory droplet transmission of an avian-human H9N2 influenza A virus. Proc Natl Acad Sci USA 106:7565-7570. https://doi.org/10.1073/ pnas.0900877106

Sun K, Ye J, Perez DR, Metzger DW (2011) Seasonal FluMist vaccination induces cross-reactive T cell immunity against H1N1 (2009) influenza and secondary bacterial infections. J Immunol 186(2):987-993. https://doi. org/10.4049/jimmunol.1002664

Tapia F, Vazquez-Ramirez D, Genzel Y, Reichl U (2016) Bioreactors for high cell density and continuous multi-stage cultivations: options for process intensification in cell culture-based viral vaccine production. Appl Microbiol Biotechnol 100(5):2121-2132. https://doi.org/10.1007/s0025 3-015-7267-9

Ulmer JB, Valley U, Rappuoli R (2006) Vaccine manufacturing: challenges and solutions. Nat Biotechnol 24(11):1377-1383. https://doi.org/10.1038/ nbt1261 
van Wielink R, Kant-Eenbergen HC, Harmsen MM, Martens DE, Wijffels RH, Coco-Martin JM (2011) Adaptation of a Madin-Darby canine kidney cell line to suspension growth in serum-free media and comparison of its ability to produce avian influenza virus to Vero and BHK21 cell lines. J Virol Methods 171(1):53-60. https://doi.org/10.1016/j.jviromet.2010.09.029

Wang H, Guo S, Li Z, Xu X, Shao Z, Song G (2017) Suspension culture process for H9N2 avian influenza virus (strain Re-2). Arch Virol 162(10):3051-3059. https://doi.org/10.1007/s00705-017-3460-8

Zost SJ, Parkhouse K, Gumina ME, Kim K, Diaz Perez S, Wilson PC, Treanor JJ, Sant AJ, Cobey S, Hensley SE (2017) Contemporary H3N2 influenza viruses have a glycosylation site that alters binding of antibodies elicited by egg-adapted vaccine strains. Proc Natl Acad Sci USA 114(47):1257812583. https://doi.org/10.1073/pnas.1712377114

\section{Publisher's Note}

Springer Nature remains neutral with regard to jurisdictional claims in published maps and institutional affiliations.

\section{Submit your manuscript to a SpringerOpen ${ }^{\circ}$ journal and benefit from:}

- Convenient online submission

- Rigorous peer review

- Open access: articles freely available online

- High visibility within the field

- Retaining the copyright to your article

Submit your next manuscript at $\boldsymbol{\nabla}$ springeropen.com 